\title{
Domestic Firms, Exporters and Importers: A Systemic Perspective
}

\author{
Jeffrey Yi-Lin Forrest ${ }^{1}$, Michael E. Trebing ${ }^{2}$, Anindya Chatterjee ${ }^{1}$, Joachim Wagner ${ }^{3,4}$ \\ ${ }^{1}$ School of Business, Slippery Rock University, Slippery Rock, PA, USA \\ ${ }^{2}$ Research Department, Federal Reserve Bank of Philadelphia, Philadelphia, PA, USA \\ ${ }^{3}$ Leuphana University, Lueneburg, Germany \\ ${ }^{4} \mathrm{CESIS}$, KTH, Stockholm, Sweden \\ Email: Jeffrey.forrest@sru.edu, mike.trebing@phil.frb.org, Anindya.chatterjee@sru.edu, wagner@leuphana.de
}

How to cite this paper: Forrest, J.Y.-L., Trebing, M.E., Chatterjee, A. and Wagner, J. (2019) Domestic Firms, Exporters and Importers: A Systemic Perspective. Theoretical Economics Letters, 9, 649-674. https://doi.org/10.4236/tel.2019.94044

Received: November 27, 2018

Accepted: March 26, 2019

Published: March 29, 2019

Copyright $\odot 2019$ by author(s) and Scientific Research Publishing Inc. This work is licensed under the Creative Commons Attribution International License (CC BY 4.0). http://creativecommons.org/licenses/by/4.0/

\begin{abstract}
Based on the exponentially growing literature in recent years on international trade and firm performance, this paper develops a general theory for this area based on systemic logic and game theory. After developing two theorems on the dynamics of the domestic market, we direct our attention to establishing results on exports to either less developed or advanced markets. Finally, a general theory is formulated regarding international trade (exports and imports) that includes selected indices of firm performance (productivity, profitability, wages, and survival). In addition to confirming empirical findings in the literature, we also delineate some suggestions for future research. This paper introduces systemic thinking into the study of international trade that is expected to provide a much needed framework for public debates and policy decision making.
\end{abstract}

\section{Keywords}

Market Competition, Productivity, Profitability, Sunk Cost, Systemic Yoyo, Wage

\section{Introduction}

International business activities and performance of firms have been a hot topic of research in recent years; and the relevant literature, both empirical and theoretical, has been growing exponentially. The empirical branch of the literature was initiated by Bernard and Jensen [1], and the theoretical branch by Melitz [2]. For recent reviews on the related research, please see [3] for empirical studies and [4] for theoretical investigations. Due to the ongoing globalization of economies 
from around the world, investigations on this research topic have been helping not only relevant academic discussions but also public debates and policy decision making, because of their importance for local, regional, national, and international economic developments. Therefore, it is both theoretically and practically important for us to establish a general theory that integrates the findings reported in the literature while providing guidelines for applications and future research.

Limited by the length of this paper, however, such an attempt has to be selective and focused on a few related topics. By employing systems science and game theory, this paper specifically focuses on

- Competitive dynamics of the domestic market;

- Exporting to either less developed markets or advanced markets; and

- Formulation of a general theory on international trade and performance of firms, where firms' outcomes, such as productivity, profitability, employees' wages, and survival are specifically addressed.

One of the most important contributions this paper makes to the existing international business literature is the introduction and application of systems science (especially, the systemic yoyo model) to the study of international activities and performance of firms. In addition to creating a brand new perspective of looking at the international business activities, the introduction and application of systems science make the relationship between firms' international activities (export, import, or both) and dimensions of firms' performance more intuitive, specifiable, predictable, and repeatable so that managerial decision making could become more timely and reliable. This has tremendous practical implications considering the fact that firms' competitive advantages are no longer sustainable, and have been becoming transient [5].

Completely different from the approaches employed by various authors in the past, the specific systemic perspective taken in this paper stands for how we look at the issues in hands from a holistic view. Because the essence of how firms survive and grow is really consequences of how they interact with each other, our holistic perspective focuses on how organizations, as entities with internal structures, exert forces and constraints on each other. And due to the novelty of this approach, we are able to establish theoretical interesting and practically significant conclusions.

The rest of this paper is organized as follows: Section 2 introduces the basics of systems science and systemic yoyo model needed for the rest of the paper. Section 3 studies two characteristics of domestic competition. Section 4 looks at the situation of exporting to a less developed market. Section 5 investigates the situation of exporting into an advanced market. Section 6 develops a general theory of productivity, employees' wages, and survival for domestic firms, exporters, importers, and two-way traders. Section 7 draws some conclusions of our study and suggests directions for future research.

\section{Systems Science and Systemic Intuition}

To make this paper self-contained, this section introduces the basic ideas and a 
brief development history of systems science, how this science complements the conventional science to form a two dimensional spectrum of knowledge and the systemic yoyo model as the playground and intuition of systems science and applications. Because business scholars are quite familiar with game theory, the relevant details of game theory are omitted.

Historically, von Bertalanffy [6] pointed out that because the fundamental character of living things is their organization, the customary investigation of individual parts and processes cannot provide a complete explanation of the phenomenon of life. Since then, this holistic view of nature and social events has permeated the spectrum of science and technology [7]. And in the past 90 some years, studies in systems science and systems thinking have brought forward brand new understandings and discoveries to some of the major unsettled problems in science [8] [9]. Because of the proliferation of studies of wholes, parts, and their relationships, a plethora of interdisciplinary studies has appeared, revealing the development trend in modern science and technology of synthesizing all areas of knowledge into a few major blocks, and the boundaries of conventional disciplines have become blurred [10]. Underlying this trend, one can see the united effort of studying similar problems in different scientific fields on the basis of wholeness and parts, and of understanding the world in which we live by employing the point of view of interconnectedness. As tested in the past 90 plus years, the concept of systems and results of systems research have been widely accepted [11] [12].

In terms of the concept of systems, similar to how numbers and algebraic variables are theoretically abstracted, systems can also be proposed out of any and every object, event, and process. For instance, behind collections of objects, say, apples, there is a set of numbers such as 0 (apples), 1 (apple), 2 (apples), 3 (apples), ...; and behind each organization, such as a business firm, a regional economy, etc., there is an abstract, theoretical system within which the relevant whole, component parts, and their interconnectedness are emphasized. As a matter of fact, it is because of these interconnected whole and parts, the totality is known as a firm, market, industry, economy, etc. In other words, when internal structures can be ignored, numbers and algebraic variables can be very useful; otherwise the world consists of dominantly systems (or structures or organizations).

When the traditional science is combined with systems science that investigates system hood, that collectively gives rise of a 2-dimensional spectrum of knowledge, where the traditional science, which is classified by the thing hood it studies, constitutes the first dimension, and the systems science, which investigates structures and organizations, forms the genuine second dimension [12]. In other words, systems research focuses on those properties of systems and associated problems that emanate from the general notion of structures and organizations, while the division of the traditional science has been done largely on properties of particular objects. Therefore, the former naturally transcends all the disciplines of the classical science and becomes a force making the existing 
disciplinary boundaries irrelevant and superficial.

The importance of this second dimension of knowledge cannot be in any way over-emphasized. By making use of this extra dimension, the exploration of knowledge has gained additional strength in terms of the capability of solving more problems that have been challenging the very survival of the mankind since the beginning of time. Such strong promise that systems research holds relies materialistically on the particular speaking language and thinking logic-the systemic yoyo model [13], Figure 1, similar to how the Cartesian coordinate system plays its role in the development of modern science [14].

Specifically, the systemic yoyo model was initially developed on the basis of the blown-up theory [15] and the discussion on whether or not the world can be seen from the viewpoint of systems [16] [17]. In this model, the concepts of black holes (or inputs), big bangs (or outputs), and converging and diverging eddy motions are coined together in the yoyo model shown in Figure 1 for each object and every system imaginable. That is, each system is a multi-dimensional entity that spins about its axis. If we fathom such a spinning entity in our 3-dimensional space, we will have a structure as artistically shown in Figure 1(a). The black hole (or input) side pulls in all things, such as materials, information, energy, profit, etc. After funneling through the "neck", all things are spit out in the form of a big bang (or outputs). Some of the materials, spit out from the end of big bang, never return to the other side and some will (Figure 1(b)). For the sake of convenience of communication, such a structure as shown in Figure 1(a), is referred to as a (Chinese) yoyo due to its general shape.

What this systemic yoyo model says is that each physical or intellectual entity in the universe, be it a tangible or intangible object, a living being, an organization, a culture, a civilization, etc., can all be seen as a kind of realization of a certain multi-dimensional spinning yoyo with an eddy field around. It stays in a constant spinning motion as depicted in Figure 1(a). If it does stop its spinning, it will no longer exist as an identifiable system. What Figure 1(c) shows is that due to the interaction between the eddy field, which spins perpendicularly to the axis of spin, of the model, and the meridian field, which rotates parallel to axis of spin, all the materials that actually return to the black-hole side travel along a spiral trajectory.

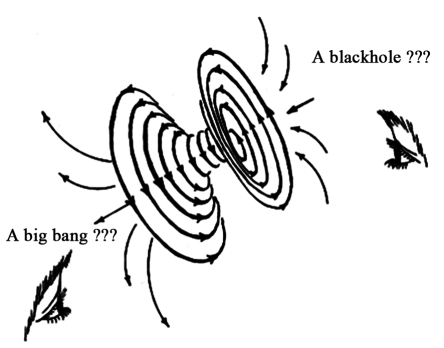

(a)

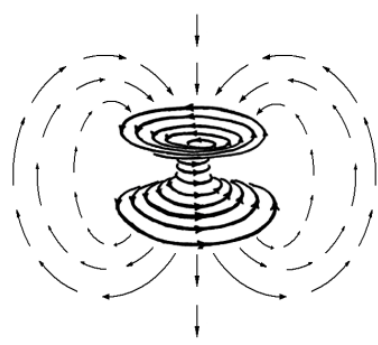

(b)

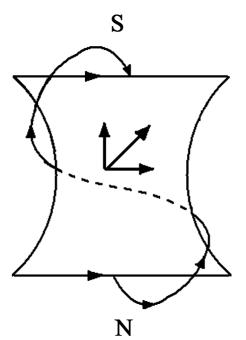

(c)

Figure 1. (a) Eddy motion model of the general system; (b) The meridian field of the yoyo model; (c) The typical trajectory of how matters return. 
As expected, this yoyo model has successfully played the role of intuition and playground for scholars who investigate the world and explore new knowledge holistically, just as what the Cartesian coordinate system did for the traditional science [7] [18] [19] [20] [21] [22]. In particular, this yoyo model of general systems has been successfully applied in the investigation of Newtonian physics of motion, the concept of energy, economics, finance, history, foundations of mathematics, small-probability disastrous weather forecasting, civilization, business organizations, the mind, among others. Along this same line of logic, in this paper we will use this model as our intuition to establish our conclusions.

\section{Domestic Competition}

This section establishes the fact that to expand into foreign markets, it is necessary for the exporting firm to first stabilize its domestic market position.

Assume that the oligopoly market of our concern consists of $m$ firms, $m=1,2, \cdots$, providing consumers with mutually substitutable products, with their respective shares of loyal consumers. To protect their turfs while potentially increase their consumer bases, they compete over the price switchers with adjustable prices charged to their customers in order to deter the potential entry of new competitions [23]. So, assume that these firms produce horizontally differentiated products at constant marginal costs, which is set to zero without loss of generality. Assume consequently the managements of these $m$ firms are well aware of the pricing strategies of the other firms and have established their best responses by playing the Nash equilibrium through pure self-analyses.

So, without loss of generality, let us consider the aggregate of the incumbent firms as one firm, whose share of occupancy of the market is $\alpha$ so that $\beta=1-\alpha$ represents the size of the market segment of switchers who base their purchase decision on which price is lower. A special case at this junction is that the imagined aggregate firm really consists of one firm, a case of monopoly. However, even in such a case, the monopolistic firm's market occupancy $\alpha$ cannot truly be 1 due to the reason that consumers who are dissatisfied with the limited choices are in constant lookout for potential substitutes. Now, the following result holds true:

Theorem 1. In the previously described oligopoly market, a sufficient and necessary condition for at least one firm to enter the market profitably, as a competitor of the incumbent firms, is that the consumer surplus satisfies $\beta=1-\alpha>0$.

The assumed market condition generally means that the technology involved and the relevant business operations have been standardized. So, for a new small firm to enter such a market with profit potential, it is reasonable to assume that this firm has come up with a more efficient technology and/or operation that can greatly reduce the overall business expenditure. Further assume that this small entrant uniformly randomizes its price $P$ over the interval $[0,1]$ as long as the firm could make profits on the average, where the reservation price each loyal customer would pay to buy their firms' products is 1. Again, the constant 
marginal costs of this small entrant are set to zero without loss of generality.

Next let us see intuitively why such a result holds true. To this end, let us model the market place is as an abstract yoyo field, and we look at the multi-dimensional yoyo body at a distance from above either the convergent side or the divergent side, while imagine that everything here takes place in our 3-dimensional space. That is, we are looking at a pool of spinning fluid, where the word "fluid" is an abstraction of movement of all kinds of media, such as goods, information, money, credit, etc., that appear and exist in business activities. In other words, graphically one is looking at the market of concern as the pool of spinning fluid shown in Figure 2.

Associated with this end of intuition, the well-known dishpan experiment, which was initially conducted successfully by Raymond Hide [24] of Cambridge University, England, and then by Dave Fultz and his colleagues of University of Chicago [25] independently, shows that when the movement of the fluid within the rotational dish is under enough pressure created by either the sufficient speed of rotation or sufficient difference in the temperature between the center and the periphery of the dish, the pattern of uniform movement, as shown in Figure 2, will develop into the chaos, as shown in Figure 3. The number of local eddy leaves is determined either by the rotational speed or by the temperature difference or both and increases with the speed and the temperature difference.

Now, the systemic modeling and laboratory experiment suggest that the fluid nowhere within this spinning dish could avoid being disturbed by the flows, either orderly or chaotically, of the pan. Also, being disturbed regionally means that a local flow pattern will inevitably appear.

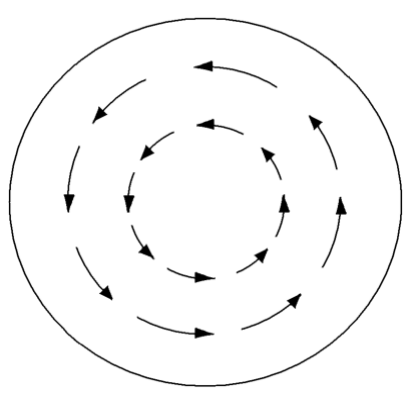

Figure 2. The systemic birdseye view of our marketplace of a previously prosperous market.

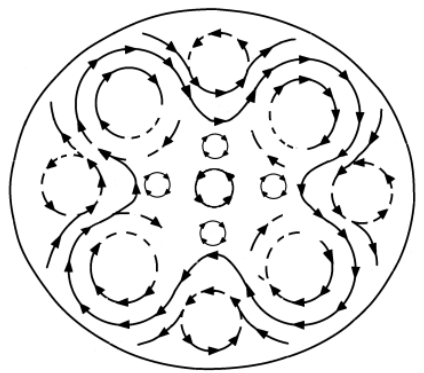

Figure 3. Asymmetric flow observed in Fultz's dishpan experiment. 
Proof. $(\Rightarrow)$ Suppose that by randomizing its price over the interval $[0,1]$ a small firm enters into the oligopoly market of $m$ firms, which are collectively seen as one aggregate firm, because these $m$ firms are in a state of mutual forbearance [26]. So, the consumer surplus must satisfy $\beta=1-\alpha>0$.

$(\Leftarrow)$ Assume that the consumer surplus satisfies $\beta=1-\alpha>0$. Firstly, let $\alpha_{0}$ be a real number so that $\beta=1-\alpha>\alpha_{0}>0$, and $\alpha=\ell \alpha_{0}$, where $\ell$ is a large natural number, indicating that the market has been largely taken by the incumbent firms.

Secondly, let us imagine that the aggregate firm is divided into $\ell$ many identical "firms", named $i, i=1,2, \cdots, \ell$. Each of them provides consumers with identical products and enjoys the market share $\alpha_{0}=\alpha / \ell$ of loyal consumers. These imaginary firms compete over the switchers with adjustable prices. Because these imaginary firms are really equal partitions of the same aggregate firm, they have the same constant marginal cost, which is set to zero without loss of generality, the managements of these firms are fully aware of the pricing strategies used by all the firms (because the firms are managed by the same administrative unit), and they establish their best, identical responses by playing the Nash equilibrium through their unified self-analyses.

Thirdly, these $\ell$ imaginary firms do not have any symmetric pure strategy Nash equilibrium. (For the setup here, there is no need to consider asymmetric pure strategy Nash equilibrium, because all these imaginary firms take identical actions). In fact, for any symmetric pure strategy portfolio $\left(x_{1}, x_{2}, \cdots, x_{\ell}\right)$, where $x_{i}=x_{j}$, for $i, j=1,2, \cdots, \ell$, a randomly chosen Firm $j(\in\{1,2, \cdots, \ell\})$ can slightly lower its price from $x_{j}$ to $x_{j}^{\prime}$ to produce additional profits for all the firms as long as $x_{j}^{\prime} \beta>\left(x_{j}-x_{j}^{\prime}\right) \alpha$, which is possible to do by adjusting $x_{j}^{\prime}$ sufficiently close to $x_{j}$. So, $\left(x_{1}, x_{2}, \cdots, x_{\ell}\right)$ is not an Nash equilibrium. Even so, [23] shows that these $\ell$ firms do have a symmetric mixed-strategy Nash equilibrium.

For the rest of this proof, it suffices to show that there is one small firm that will be expected to profit by entering this market through uniformly randomizing its price strategy over the interval $[0,1]$.

Let $F(P)$ be the price distribution of Firm $j$, one of the imaginary firms of the aggregate firm. The aggregate firm or equivalently each of the $\ell$ imaginary forms sets its price after taking into account the price of the new firm and those of all other imaginary firms. Hence, the profits for Firm $j$ from its loyal consumers is $\alpha_{0} P$ and those from its share of the switchers is $\Pi_{i \neq j}^{\ell}(1-P)[1-F(P)] \beta P=\beta P(1-P)[1-F(P)]^{\ell-1}$. Hence, the profits $\Pi$ Firm $j$ generates when the firm sells its product at price $P$ are

$$
\alpha_{0} P+\beta P(1-P)[1-F(P)]^{\ell-1}
$$

and the objective function of Firm $j$ is

$$
\begin{aligned}
\max _{F(P)} E(\Pi) & =\int_{-\infty}^{+\infty}\left\{\alpha_{0} P+\beta P(1-P)[1-F(P)]^{\ell-1}\right\} \mathrm{d} F(P) \\
& =\int_{0}^{1}\left\{\alpha_{0} P+\beta P(1-P)[1-F(P)]^{\ell-1}\right\} \mathrm{d} F(P)
\end{aligned}
$$


where $E(\Pi)$ stands for Firm $j$ s expected profits for all possible prices, and the objective for Firm $j$ is to maximize its expected profits by choosing its price distribution $F(P)$. The reason why the upper and lower limits of the integral are changed respectively from $+\infty$ and $-\infty$ to 1 and 0 is because when $P<0$ or when $P>1$, the profits are zero.

The equilibrium indifference condition of Firm $j$ is

$$
\alpha_{0} \times P+\beta \times P(1-P)[1-F(P)]^{\ell-1}=\alpha_{0} \times 1
$$

So, for the $\ell$ imaginary firms, solving Equation (1) leads to their symmetric equilibrium pricing strategy as follows:

$$
F(P)=1-\left(\frac{\alpha_{0}}{\beta P}\right)^{\frac{1}{\ell-1}}
$$

From $\beta>\alpha_{0}$, it follows that $\alpha_{0} / \beta<1$. So, for any Price $P$, satisfying $1 \geq P \geq \alpha_{0} / \beta$, Equation (2) is a well-defined probability distribution. This end implies that for the $\ell$ imaginary firms, or equivalently, the aggregate firm, the lowest allowed price is $\alpha_{0} / \beta$.

To complete this proof, it suffices to show that the small entrant actually expects to make profits in this new market. To this end because $\lim _{P \rightarrow 1^{-}} F(P)=1-\left(\alpha_{0} / \beta\right)^{1 /(\ell-1)} \neq F(1)=1$, the cumulative price distribution function $F(P)$ has a jump discontinuity at the reservation value $P=1$, where the amount of jump is $\left(\alpha_{0} / \beta\right)^{1 /(\ell-1)}$. That is, $F(P)$ has a mass point of size $\left(\alpha_{0} / \beta\right)^{1 /(\ell-1)}$ at the reservation price $P=1$. So, the expected profits of the small entrant are the following:

$$
\begin{gathered}
E(\Pi)=\int_{0}^{\alpha_{0} / \beta} \beta P \mathrm{~d} P+\int_{\alpha_{0} / \beta}^{+\infty} \beta P[1-F(P)]^{\ell} \mathrm{d} P \\
=\int_{0}^{\alpha_{0} / \beta} \beta P \mathrm{~d} P+\int_{\alpha_{0} / \beta}^{1} \beta P[1-F(P)]^{\ell} \mathrm{d} P+\beta\left(\frac{\alpha_{0}}{\beta}\right)^{\ell /(\ell-1)}
\end{gathered}
$$

where the first term in the right-hand side of Equation (3a) stands for the expected profits of the small entrant when it charges the lowest price in the marketplace and captures the entire segment of the switchers, and the second term is the small entrant's expected profits when it is in direct competition with the $\ell$ incumbent firms.

Because the first term in the right-hand side of Equation (3b) satisfies

$$
\int_{0}^{\alpha_{0} / \beta} \beta P \mathrm{~d} P=\frac{\alpha_{0}^{2}}{2 \beta}>0
$$

the second term is $\geq 0$, because the integrant is positive and the third term is positive, it can be concluded that the expected profits of the small entrant $E(\Pi)$ is greater than zero. This end implies that if the consumer surplus $\beta=1-\alpha>0$, there will be at least one small entrant that will enter the market to compete with the incumbent firms. QED

The practical significance of Theorem 1 is that although the market is entirely occupied by the incumbents that compete over the switchers, who at the same 
time are content with the existing product, there is still a chance for a new company to enter the market profitably. And the size of the entrant will be proportional to that of the market segment of switchers.

Theorem 2. In the Nash equilibrium, when the competition of the market grows with an increasing number of firms entering the market, the base of loyal customers for each incumbent firm will gradually and eventually diminish.

Proof. This market does not have any pure strategy Nash equilibrium and nonsymmetrical mixed strategy Nash equilibrium [23]. Let $F_{i}(P)$ stand for the price distribution of Firm $i, i \in\{1,2, \cdots, m\}$, which compete with each to attract switchers (Theorem 1). The assumption that an increasing number of firms enter the market implies that the consumer surplus satisfies $\beta=1-m \alpha>0$ (Theorem 1), where $\alpha$ is assumed to be the market share of loyal customers of Firm $i$. Assume that there are $n$ new firms that enter the market by uniformly randomizing its price $P$ over the interval $[0,1]$, where their cost basis is also assumed to be constant and set to zero. Then, the profits of incumbent Firm $i$ are given by

$$
\alpha P+\beta P(1-P)^{n} \prod_{j \neq i}^{m}\left[1-F_{j}(P)\right]
$$

and the objective function of incumbent Firm $i$ is

$$
\max _{F_{i}(P)} E\left(\Pi_{i}\right)=\int_{0}^{1}\left\{\alpha P+\beta P(1-P)^{n} \prod_{j \neq i}^{m}\left[1-F_{j}(P)\right]\right\} \mathrm{d} F_{i}(P)
$$

The equilibrium indifference condition for incumbent Firm $i$ is

$$
\alpha \times P+\beta \times P(1-P)^{n} \prod_{j \neq i}^{m}\left[1-F_{j}(P)\right]=\alpha \times 1
$$

So, the symmetric equilibrium price strategy of each incumbent Firm $i$, $i=1,2, \cdots, m$, is

$$
F(P)=F_{i}(P)=1-P^{\frac{-1}{m-1}}(1-P)^{-\frac{n-1}{m-1}}\left(\frac{\alpha}{\beta}\right)^{\frac{1}{m-1}}=P^{\frac{-1}{m-1}}(1-P)^{-\frac{n-1}{m-1}} h(P)
$$

where $h(P)=P^{\frac{1}{m-1}}(1-P)^{\frac{n-1}{m-1}}-\left(\frac{\alpha}{\beta}\right)^{\frac{1}{m-1}}$.

For this strategy $F(P)$ to be valid, we must have $F(P)=0$, for $P \leq \underline{P}$, $F(P)=1$, for $P \geq \bar{P}$, and $F(P) \geq 0$, for $\underline{P} \leq P \leq \bar{P}$, where $\underline{P}$ and $\bar{P}$ are some fixed price levels such that $0 \leq \underline{P}<\bar{P} \leq 1$.

For such price levels $\underline{P}$ and $\bar{P}$ to exist, $h(P)$ must satisfy the following: $h(P) \geq 0$, for $\underline{P} \leq P \leq \bar{P}$, where $\underline{P}$ and $\bar{P}$ are some fixed price levels such that $0 \leq \underline{P}<\bar{P} \leq 1$, and that $h(0)<0$ and $h(1)<0$. Since

$$
h^{\prime}(P)=\frac{1}{m-1} P^{\frac{1}{m-1}}(1-P)^{\frac{n-1}{m-1}}\left[P^{-1}-(n-1)(1-P)^{-1}\right]
$$

it can be shown that $h(P)$ reaches its maximum at $P=1 / n$. That is, in order for the previously mentioned price levels $\underline{P}$ and $\bar{P}$ to exist, $h(P)$ must satisfy $h\left(\frac{1}{n}\right)>0$, which means 


$$
\frac{\alpha}{\beta}<\frac{1}{n}\left(1-\frac{1}{n}\right)^{n-1}=\left(1-\frac{1}{n}\right)^{n}\left(1-\frac{1}{n}\right) \frac{1}{n} .
$$

So, when $n \rightarrow \infty, \alpha / \beta \rightarrow(1 / e) \times 1 \times 0=0$. This end means that the base of loyal customers for each incumbent firm gradually diminishes when an increasing number of new firms enter the market. QED

The results in Theorems 1 and 2 paint a very dynamic picture of competition in the domestic market. In particular, if incumbent firms do not compete within the domestic market over the consumer surplus, then new competitions will enter the market. Also, when the number of firms that compete within the market increases, the market share of each firm will diminish. In other words, no matter whether a firm plans to export into any foreign market or not, it has to first stabilize its domestic market share, which is its home base on which bigger plans can be dreamed of and can next be implemented. In terms of the systemic yoyo model, what these two theorems say is that when the market competition intensifies, the number of eddy leaves in Figure 3 will increase while the size of each of the leaves gets smaller until they become not clearly visible. This result is exactly what is shown in the laboratory, that is, when the difference between the periphery and the center of the spinning dish increases, the number of eddy leaves will increase until the leaves become so small that they are no longer visible [27].

\section{Exporting into a Less Developed Market}

In this paper, a less developed foreign market represents a foreign market that it is not as well developed economically and is not as well serviced with quality products as is the domestic market. That is, the functionality of the products, exported into such a foreign market, can be adjusted according to the existing market situation so that sufficient savings can be generated to cover all the sunk costs of entering the foreign market. The range of extra sunk costs includes those of transportation, distribution, marketing, and personnel with skill to manage foreign networks. These costs provide an entry barrier into foreign markets for less resourceful firms to overcome. That indirectly implies that for a firm to successfully export its products into a foreign market, the firm has to be more productive than non-exporting firms of the same size from the same industry before it starts to export successfully with the additional sunk costs comfortably absorbed. See [1] [28] for relevant empirical confirmations of this conclusion. Here, productivity stands for the efficiency with which the firm turns inputs (labor, physical capital, energy, materials, managerial know-how) into outputs (goods, services).

In other words, when competing with local firms $i(=1,2, \cdots, m)$ of the receiving economy, we can also assume that our exporting firm and local firms produce their products that are horizontally differentiated at constant marginal costs, which is set to zero without loss of generality. As before, assume that each local firm enjoys a base of loyal customers of size a, $\beta=1-m \alpha$ is the size of 
the market segment of price switchers, and that the managements of these $m+1$ firms are well aware of the pricing strategies of the other firms and have established their best responses by playing the Nash equilibrium through pure selfanalyses. Because our exporting firm comes from a more advanced market, its products naturally carry a brand name in the less developed market. That is, assume that a percentage $r$ of the customers of the receiving market are brand chasers; and from being well aware of its advantageous position, the exporting firm sells its product at $k(\geq 1)$ times more than the market price $P, 0 \leq P \leq 1$, of the local firms.

Theorem 3. In the Nash equilibrium, if the consumer surplus of the local market satisfies $\beta=1-m \alpha>\alpha$, then the exporting firm would make profits in this less developed foreign market by randomizing the local firms' price $P$ within the interval $[0,1]$.

Proof. For local Firm $i$, its objective function is

$$
\max _{F_{i}(P)} E\left(\Pi_{i}\right)=(1-r) \int_{0}^{1}\left\{\alpha P+\prod_{j \neq i}^{m}\left[1-F_{j}(P)\right] \beta P\right\} \mathrm{d} F_{i}(P)
$$

with the equilibrium indifference condition being

$$
\alpha \times P+\beta \times P \prod_{j \neq i}^{m}(1-P)\left[1-F_{j}(P)\right]=\alpha \times 1 .
$$

So, the symmetric equilibrium pricing strategy is

$$
F(P)=1-\left(\frac{\alpha}{\beta P}\right)^{\frac{1}{m-1}},
$$

which is defined only for $1 \geq P \geq \alpha / \beta$. Now, the expected profits of the exporting firm are

$$
E[\Pi]=\int_{\alpha / \beta}^{1} r k P \mathrm{~d} P=\frac{r k}{2}\left(1-\frac{\alpha^{2}}{\beta^{2}}\right),
$$

which is positive only when $\beta=1-m \alpha>\alpha$. QED

Corollary 1. In the Nash equilibrium, if the consumer surplus of the local market satisfies $\beta=1-m \alpha>0$, then the exporting firm would make profits in this less developed foreign market by randomizing the local firms' price $P$ within the interval $[0,1]$ even if the foreign market does not have any brand chasers.

Proof. The expected profits $E[\Pi]$ of the exporting firm would be equal to $k \beta Q$, for $0<Q<P$, where $P$ is the price at which local firms sell their products and $Q$ the price the exporting firm charges. QED

What Theorem 3 says is that only when the consumer surplus of the less developed foreign market is sufficiently large, exporting into such market will be profitable with profits equaling at least $k$ times of each of the local firm could have made before any foreign competitor appeared. Otherwise, the profits could be so, so very small that it is not worth the effort of exporting into such a foreign market as indicated in Corollary 1 considering the potential risk associated with the sunk costs.

The reason why the exporting firm randomizes the market price $P$ of the local 
firms over the interval $[0,1]$ is that without any first-hand knowledge of the new market, the firm just aims at making profits and develop its customer base. Hence, as the initial pricing strategy it is a reasonable market approach.

The conclusion of Theorem 3 can be seen readily from the systemic yoyo model. For instance, let us model the said foreign market of our concern as the entire spinning dish in Figure 3, and each of the $m$ firms a local eddy pool. Then, the symmetry that is assumed to exist in the market place, just like that that exists in the dishpan experiment, suggests that it is impossible that

1) A large blank space, which is at least as big as the area occupied by one of the local eddy leaves, would appear within the circular chain of the local eddy pools. That is, the local eddy leaves have to be evenly distributed within the spinning dish along the periphery and around the center of the dish. And,

2) The total area that borders between adjacent local eddy leaves and between the periphery of the dish and circular chain of the local eddy leaves is too big, because the appearance of the local eddy leaves is caused by uneven distributions of forces that act on the fluid particles located at different distances from the center of the dish.

\section{Exporting into an Advanced Market}

In this paper, an advanced foreign market implies a foreign market in which the quality and functionality of products imported into the market have to be the best possible of all options that are available to consumers. In other word, to export into an advanced foreign market, the sunk costs of the exporting firm have to be greater than zero. In this case, other than the costs of transportation, distribution, marketing, and personnel with the skill to manage foreign networks, the sunk costs also include those of production in improving current domestic products for consumption of the advanced foreign market. At the same time, within the advanced foreign market, the imported products represent just another alternative and do not naturally enjoy any advantage of being foreign.

Theorem 4. Assume that the consumer surplus $\beta$ of the foreign market satisfies $\beta=1-m \alpha \geq \alpha$, then there is an expected opportunity for the exporting firm to make at least as much profits as ( $\alpha$-sunk costs) in the said foreign market by uniformly randomizing its price $P$ over the interval $[0,1]$.

Proof. From $\beta=1-m \alpha \geq \alpha$, it follows that $\alpha / \beta \leq 1$. So, for any price $P$, satisfying $\alpha / \beta \leq P \leq 1$, the following function $F(P)$,

$$
F(P)=1-\left(\frac{\alpha}{\beta P}\right)^{\frac{1}{m-1}},
$$

represents a well-defined strategy for each of the $m$ local firms existing in the foreign market of concern. It satisfies the following equilibrium indifference condition of Firm $i, \quad i=1,2, \cdots, m$,

$$
\alpha \times P+\beta \times P \prod_{j \neq i}^{m}(1-P)\left[1-F_{j}(P)\right]=\alpha \times 1,
$$

which implies that for the $m$ incumbent firms in the foreign market, their lowest 
allowed price is $\alpha / \beta$.

Next, we show that there is such an opportunity that the exporting firm could expect to make at least as much revenues as $\alpha$ in the said foreign market. To this end, Equation (5) implies that $\lim _{P \rightarrow 1^{-}} F(P)=1-(\alpha / \beta)^{\frac{1}{m-1}} \neq F(1)=1$. So, the cumulative price distribution function $F(P)$ has a jump discontinuity at the reservation value $P=1$, where the amount of jump is $(\alpha / \beta)^{\frac{1}{m-1}}$. So, the expected revenue of the exporting firm in the said foreign market is the following:

$$
\begin{aligned}
E(\Pi) & =\int_{0}^{\alpha / \beta} \beta P \mathrm{~d} P+\int_{\alpha / \beta}^{+\infty} \beta P[1-F(P)]^{m} \mathrm{~d} P \\
& =\int_{0}^{\alpha / \beta} \beta P \mathrm{~d} P+\int_{\alpha / \beta}^{1} \beta P[1-F(P)]^{m} \mathrm{~d} P+\beta\left(\frac{\alpha}{\beta}\right)^{\frac{m}{m-1}} \\
& = \begin{cases}\frac{-m}{2(m-2)} \frac{\alpha^{2}}{\beta}+\frac{m-1}{m-2} \frac{\alpha^{\frac{m}{m-1}}}{\beta^{\frac{1}{m-1}}}+\beta\left(\frac{\alpha}{\beta}\right)^{\frac{m}{m-1}}, & \text { if } m \geq 3 \\
\frac{\alpha^{2}}{2 \beta}-\frac{\alpha^{2}}{\beta} \ln \frac{\alpha}{\beta}+\beta\left(\frac{\alpha}{\beta}\right)^{\frac{m}{m-1}}, & \text { if } m=2\end{cases}
\end{aligned}
$$

And because $\frac{\partial}{\partial \alpha}[E(\Pi)-\alpha]>0$ and when $\alpha=1 /(m+1)=\beta$, $E(\Pi)-\alpha>0$, it follows that there is $\alpha_{\Pi}^{*} \in(0,1 /(m+1))$ such that when $\alpha \geq \alpha_{\Pi}^{*}, E(\Pi)>\alpha$. Therefore, there is an opportunity when the expected profits of the exporting firm in the said foreign market are at least as much as ( $\alpha$-sunk costs) by uniformly randomizing its price $P$ over the interval $[0,1]$. QED

What Theorem 4 says is that when entering an advanced foreign market, to develop the necessary consumer base and to generate the baseline revenue, the exporting firm could use such a sales' strategy that it materially randomizes the selling price uniformly over the interval $[0,1]$. At the same time, this theorem and its proof imply that although it is advanced, if the market in the foreign land is expanding, one can expect capable foreign firms to enter and to compete with the incumbent local firms. On the other hand, the sunk costs for the exporting firm cannot be too big in terms of how much each local firm has been making.

After the initial foray into the advanced foreign market by randomizing its selling price over the interval $[0,1]$, the exporting firm could treat itself as one of the local firms as soon as it establishes a base of loyal customers. By doing so, the firm will be able to double its revenue in the foreign market by employing different pricing strategies [29].

\section{Discussion}

This section presents a general theory on international trades and firms' productivity, survival, and employees' wages based on the theorems established in the 
previous sections and the systemic yoyo model. What is significant here is that we theoretically derive conclusions that are observed earlier by various scholars from data mining, while provide conclusions that could potentially be confirmed by data analysis in the years to come.

\subsection{International Trade and Productivity}

The dynamic nature of the domestic market competition, developed by Theorems 1 and 2, clearly shows that it is not easy for any firm to stay afloat domestically without actively trying to attract additional customers while improving its products. Otherwise, increasing competition will wear away the established consumer base of the firm and push the firm over the edge of the market. Hence, such important issues as exporting goods to international markets have to be in the making years ahead of the actual implementation of the idea. (It is well known that most consumer products in the advanced countries are in the maturity stage of the product life cycle facing intense competition and eroding market shares. As such, firms look to exporting as an option to extend their product life cycles.) The leadership of the firm has to be a major part of such ambition and export market entry decision. Please refer to [30] for a historical account and [5] for recent reviews on the importance of leadership in export management. In other words, we would expect the quality and vision of the management team of an export starter to be different from that of a domestic firm, i.e., a firm that buys and sells only domestically.

All firms with an ambition of international reach can be categorized into two groups: those that are successful and those that are not successful. To be successful, there are definitely many hurdles to overcome. One of the first hurdles will be to muster the necessary financial resources to cover the sunk costs of potentially going abroad. Before anything else, some of the first initial sunk costs will be those used to acquire the knowledge of the particular foreign markets, the technology needed for modifying current domestic products for foreign consumption, the development of distribution centers and retail outlets, and all other strategic ground works. If all goes well, a second round of heavy investments will be needed to actually arrange transportation, purchase equipment for product modifications, establish distribution or marketing networks, and hire and train personnel that will be skillful enough to manage foreign networks.

No matter how an exporter's investments are financed, either by cash or bank loans or a combination of both, a potentially successful export starter has to be efficient in turning its inputs (labor, physical capital, energy, materials, managerial know-how) into outputs (goods) years before taking the leap into a foreign market [31] [32]. Otherwise, the needed finance for international reach cannot be secured. In order to facilitate a much greater output requirement, the export starter firm would be better equipped than non-exporters in terms of its technology and skills of its workers to accelerate its productivity growth when called for [4] [33] [34]. That explains why exporters that have low productivity would 
fail when compared to successful exporters [35] [36]. In short, our theory confirms the following hypothesis with some modification on why exporters can be generally expected to be more productive than non-exporting firms [31] [32]: Among all the firms that self-select themselves into export markets, only more productive ones tend to be successful within these markets (or only more productive firms go abroad successfully).

Likewise, in terms of the management quality of export starters, export starters would be superior to non-exporters in terms of their ability to produce with sufficiently high productivity, analyze foreign markets accurately and timely, keep abreast of technological advancements seamlessly, establish transportation and distribution centers, and recruit and train the necessary personnel to manage foreign networks. It is important to note that any of these areas of planning can either go wrong or operate inefficiently.

The knowledge acquired from foreign markets and interacting with international customers and competitors motivates exporting firms to advance its post-entry performance by improving its products via additional functionalities, adopting more efficient systems, becoming more user-friendly, among others. With successful entry into export market(s), exporting firms have to increase their outputs in order to satisfy the expanding needs of their global customer base. At the same time, the intense competition in foreign markets, which is additional to that of the domestic market, forces exporting firms to make changes faster than firms that sell their products domestically only. That is, competitive advantages become truly transient for exporting firms; they need to be disengaged in timely fashion and new advantages have to be uncovered and adopted quickly. This rapid cycle of innovation is at times difficult to accomplish for many firms [5]. As discussed in the preceding two sections, a difficult aspect of exporting is figuring out how to overcome the sunk costs of exporting, which can be affected by many extraneous factors, including international politics, policy changes, etc. In short, our theory supports the following hypothesis: Successful exporters can be expected to be more productive than non-exporting firms [31] [32] due to the enhanced learning experience acquired through exporting and drastically increased market demands in terms of management strategy and productivity. That actually also explains why exporting does not necessarily improve the firms in general ([37], p.1537), because increasing frequency of disengaging and adopting strategic advantages can practically lead to uncertainties and business disruptions [5].

Our theoretical framework offers an explanation of why there exists a different in terms of exporter premiums, the ceteris paribus percentage difference of labor productivity. It is expected that on average, the premiums would be larger for countries with lower export participation rates, with more restrictive trade policies, lower per capita GDP, less effective government and poor regulatory quality, and for countries exporting to relatively distant markets [38]. That is because these characteristics, either individually or jointly, make it more difficult 
to finance the sunk costs of exporting compared to those countries without these characteristics. In sum, to successfully finance export activities, the exporter premiums for countries with these characteristics must be high.

Similarly, the reason why firms that export to a larger number of foreign markets have to be more productive than firms that serve a smaller number of foreign markets is because of the recurrent nature of some of the sunk costs for each market. For example, transportation costs will be incurred for each destination market, local language related materials, such as user's manual and direct marketing publications, need to be prepared for each destination. Likewise, recurrent costs will be incurred to comply with local regulations in each target market and so on.

Theorems 3 and 4 jointly explain why exporters to developed economies have superior ex-ante productivity levels than non-exporters and firms exporting to less developed countries. It is because when exporting to relatively developed economies, none of the sunk costs can be easily recovered simply by modifying the products for foreign consumption; at the same time, additional expenses are incurred in order to upgrade the products designed and produced for domestic consumption to the need of consumers of the developed economies. That is, superior ex-ante productivity levels are needed for firms to finance their exporting initiatives. In terms of different learning-by-exporting effects by varying export destinations, these theorems imply that exporting to advance economies foster higher levels of productivity than exporting to less developed countries, because the former destinations force exporters to satisfy more advanced consumer demands along with greater challenges of the local competitors than the latter.

In terms of the relationship between import and productivity, a similar theory as the one just developed above also holds true, because for a firm to start importing, it also has to first cover the relevant sunk costs, including, but not limited to, finding potential foreign suppliers, inspection of goods, negotiations, contract formulation, learning and acquisition of customers, etc., [39] [40] [41]. In other words, in order to import goods successfully, higher productivity has to be a prerequisite for the importing firm. That is, more productive firms have the potential to foray into import markets successfully.

At the same time, through importing, the firm can exploit global specialization and use inputs from the forefront of knowledge and technology. That would surely impact the productivity of the firm positively. That is, other than desired goods that are either not available or better than those available in the domestic market, the importing firm also acquires new knowledge and technology that are useful and advantageous for the firm to compete domestically.

Because importing successfully requires high levels of productivity and helps further increase productivity, it would very well lead the importing firm into export markets. That is why successful two-way traders tend to be the most productive firms on average [40] [41] [42] [43]. Hence, firms can be ordered in descending levels of productivity as follows: Two-way (import and export) trad- 
ers, one-way players (either import or export), and domestic firms.

\subsection{International Trade and Employee Wages}

Based on what has been discussed in Subsection 6.1 we can generally conclude that exporters tend to be more productive than domestic firms even before the former enter export markets for the reason that they need to muster sufficient financial resources to cover the sunk costs that domestic firms do not ever have to worry about. So, we can assume collectively (not individually) that exporters have more financial resources than do domestic firms at least during those several years prior to their entry into export markets.

Let Firm A be a "would-be" or successful exporter and Firm B a non-exporter. Assume that each of them produces only one product. Then the profits of each firm $i(=\mathrm{A}, \mathrm{B})$ from the product are given by

$$
P^{i p}=n^{i p}\left(p_{s}^{i p}\right)\left(p_{s}^{i p}-p_{p}^{i p}\right),
$$

where $p_{s}^{i p}$ is the unit selling price, $p_{p}^{i p}$ the total unit cost, and $n^{i p}\left(p_{s}^{i p}\right)$ the number of units sold at price $p_{s}^{i p}$.

For Firm A, its market demand for its product is given as follows by maximizing Equation (7):

$$
n^{A p}\left(p_{s}^{A p}\right)=n^{A p}\left(p_{s_{0}}^{A p}\right) \frac{p_{s_{0}}^{A p}-p_{p}^{A p}}{p_{s}^{A p}-p_{p}^{A p}}(\text { units }),
$$

where $n^{A p}\left(p_{s_{0}}^{A p}\right)$ is the initial market demand at the initial selling price $p_{s_{0}}^{A p}$. And the profits are

$$
P^{A p}=n^{A p}\left(p_{s_{0}}^{A p}\right)\left(p_{s_{0}}^{A p}-p_{p}^{A p}\right)
$$

So, as the sales price $p_{s}^{A p}$ lowers to the cost $p_{p}^{A p}$, the demand approaches infinity. If $\left(p_{s_{0}}^{A p}-p_{p}^{A p}\right)$ stays constant, then the lower the sales price $p_{s}^{A p}\left(>p_{p}^{A p}\right)$, the greater the demand $n^{A p}\left(p_{s}^{A p}\right)$, and the greater the total profits $p^{A p}$.

Similarly, Firm A's staffing need is given by

$$
n^{A w}\left(p_{s}^{A w}\right)=n^{A w}\left(p_{s_{0}}^{A w}\right) \frac{p_{s_{0}}^{A w}-p_{p}^{A w}}{p_{s}^{A w}-p_{p}^{A w}}(\text { perons })
$$

and the total profits from hiring $n^{A w}\left(p_{s}^{A w}\right)$ are

$$
P^{A w}=n^{A w}\left(p_{s_{0}}^{A w}\right)\left(p_{s_{0}}^{A w}-p_{p}^{A w}\right),
$$

where $n^{A w}\left(p_{s_{0}}^{A w}\right)$ stands for the firm's initial need for additional staffing to be hired at the initial expected revenue $p_{s_{0}}^{A w}$ per employee, $p_{p}^{A w}$ the per-employee cost, and $p_{s}^{A w}$ the ongoing expected revenue generated by an employee.

Equations (10) and (11) imply that when the difference $\left(p_{s}^{A w}-p_{p}^{A w}\right)$ decreases, the need for more employees increase and the profits generated by the employees grow. Now, $\left(p_{s}^{A w}-p_{p}^{A w}\right) \rightarrow 0$ implies that when the $p_{s}^{A w}$-value is relatively stable, $p_{p}^{A w}$ should be increased as much as possible. That is, em- 
ployees' wages and benefits can go up so that the total per-employee cost can approach the expected per-employee revenue $p_{s}^{A w}$ as much as possible.

When the $p_{p}^{A w}$-value increases, the per-unit product cost $p_{p}^{A p}$ will also rise accordingly. But equations (8) and (9) indicate that as long as the difference $\left(p_{s_{0}}^{A p}-p_{p}^{A p}\right)$ does not change much while $\left(p_{s}^{A}-p_{p}^{A}\right)$ drops, the total profits from the product will continue to go higher. That is, our analysis leads to the following results:

Theorem 5. If a firm is well funded, assuming all other aspects of the business operation stay the same, then

1) The market demand for the product increases as the unit-selling price drops close to the unit cost basis, while the total profits increase drastically; and

2) The firm will hire additional employees at higher than competitive wage rates and better benefits with the total profits soaring. QED

The systemic intuition behind Equations (7) and (10) is that beside the fact that products of Firm A generate profits, other main stakeholders of the firm should more or less and directly or indirectly contribute to the profits making.

Next, let us look at Firm B, which is of limited financial resources. In this case, its profits are given by the following:

$$
P_{\text {total }}^{B}=P^{B p}+P^{B w}=n^{B p}\left(p_{s}^{B p}\right)\left(p_{s}^{B p}-p_{p}^{B p}\right)+n^{B w}\left(p_{s}^{B w}\right)\left(p_{s}^{B w}-p_{p}^{B w}\right)
$$

subject to the budget constraint

$$
n^{B p}\left(p_{s}^{B p}\right) p_{p}^{B p}+n^{B w}\left(p_{s}^{B w}\right) p_{p}^{B w}=I
$$

where $I$ stands for the total financial resources available to Firm B. By maximizing this problem, we establish the following results:

$$
\begin{aligned}
n^{B p}\left(p_{s}^{B}\right) & =\frac{n_{p}^{B p}\left(p_{s_{0}}^{B p}\right) p_{s_{0}}^{B p}}{p_{s}^{B p}} \\
n^{B w}\left(p_{s}^{B w}\right) & =\frac{n^{B w}\left(p_{s_{0}}^{B w}\right) p_{s_{0}}^{B w}}{p_{s}^{B w}}
\end{aligned}
$$

and

$$
P_{\text {total }}^{B}=n^{B p}\left(p_{s_{0}}^{B p}\right) p_{s_{0}}^{B p}\left(1-\frac{p_{p}^{B p}}{p_{s}^{B p}}\right)+n^{B w}\left(p_{s_{0}}^{B w}\right) p_{s_{0}}^{B w}\left(1-\frac{p_{p}^{B w}}{p_{s}^{B w}}\right),
$$

where $p_{s_{0}}^{B p}, n^{B p}\left(p_{s_{0}}^{B p}\right), p_{s_{0}}^{B w}$, and $n^{B w}\left(p_{s_{0}}^{B w}\right)$ are defined similarly as in the analysis of Firm A above.

Equation (14) indicates that to expand the market demand, Firm B has to decrease its unit selling price. Because its financial resources are limited, Firm B has a limited ability to invest in its product. That is, Firm B cannot afford to compete with Firm A that has way more resources. Similar to the situation of Firm A, Firm B can also increase its profits by reducing its selling price $p_{s}^{B p}$, if it can keep the unit profit $\left(p_{s}^{B p}-p_{p}^{B p}\right)$ constant. However, unlike the case with Firm A, the level of profits for Firm B is capped at $n^{B p}\left(p_{s_{0}}^{B p}\right) p_{s_{0}}^{B p}$ (Equation (16)). A comparison between Firms A and B, we can see the following: 
1) While Firm A is promoting its product to expand its market share and appearance, Firm B cannot afford to devote much of its scarce resources to do so. One reason is that it does not have much money to allocate for the purpose of promotion. And another reason is that, as Equation (16) indicates, an excessive amount of spending will keep its unit selling price $p_{s}^{B p}$ high. So, to increase its profits, Firm B has to control its spending so that its profits can be maximized by lowering its unit selling price $p_{s}^{B p}$.

2) While Firm A is placing large orders at much reduced wholesale price, Firm B just cannot take such opportunities. Similarly, other volume-related savings are not available to Firm B.

Equation (15) indicates that to hire more employees, Firm B has to lower the average expected per-worker revenue. Because of its limited financial resources, this result implies that Firm B has to limit how many workers it can afford to hire. To maximize its profits in the dimension of human resources, Equation (16) implies that $p_{s}^{B w} \gg p_{p}^{B w}$ must hold true. So, for Firm B, it can either hire a relatively large number of employees at low wage rates or hire a relatively small number of high-quality employees at a relatively high wage rates. For the latter to occur, the employees' productivity has to be very high, which in general means that Firm B needs to invest a great deal in technology that needs to be constantly updated. And this end might not be possible due to Firm B's limited financial resources. That is, the high-quality employee option may never be practically possible for Firm B to take.

By comparing Equations (11) and (16), the following results can be seen:

1) Firm A can spend extra money on employees' retraining programs to lower the average per-employee cost basis $p_{p}^{A w}$, while Firm B cannot. This is because in the latter case, extra spending on employees' training programs increase both $p_{s}^{B w}$ - and $p_{p}^{B w}$-values. So, the ratio $p_{p}^{B w} / p_{s}^{B w}$ might not change in the favorable direction to Firm B. (Parallel to this conclusion is that Firm A can drastically reduce the average per-employee costs basis by simply engaging in outward foreign direct investments, which could very possibly involve investments in capital goods).

2) Similar reasoning indicates that Firm A can afford to invest in programs that make its employees feel good and to raise their morale, while Firm B cannot afford such luxuries. Consequently, employees of Firm A produce more than those of Firm B.

3) While Firm A hires a larger number of employees so that it can easily reduce its per-employee benefits costs, Firm B with fewer employees has to pay the inflated market prices for the same benefit packages. That is, volume savings are not available to Firm B.

This analysis explains why in a firm, if one occupation is highly paid, so are all other occupations. In particular, if one occupation is paid at a level above the competitive wage rate, then all other occupations within the firm, including those playing supporting roles, would most likely be also paid at levels above their corresponding competitive wage rates. The increased productivity from the 
central occupation will be more than enough to finance the supporting occupations so that their respective wages are higher than those occupations' competitive market rates. For a relevant study and the literature on inter-industry wage differentials [7].

Now, let us look at the relationship between international trade and employee wages. From Theorem 5,it follows that if we look at successful exporters of all sizes from economies at different developmental stages, they would tend to pay higher wages and better benefits than those of non-exporters [1] [31] [44] [45] [46]. It should be emphasized that for this conclusion to hold true, the key words are "successful exporters." Since not all exporters are successful and not all successful exporters are financially resourceful at all times (Theorems 3 and 4), what is developed above only holds true for "successful exporters".

\subsection{International Trade and Firms' Survival}

In this subsection, we consider the following two questions:

1) Does the productivity advantage of firms involved in international trade lead to a profitability advantage for these firms when compared to otherwise identical domestic firm seven though international firms incur extra costs and pay higher wages? And

2) Would firms involved in international trades be more likely to survive as a business compared to those that are domestic-only firms?

It is clear that profitability has to be supported by productivity. However, productivity is only one of several possible idiosyncratic factors that determine profits [47]. In other words, the success of firms in general depends directly on profitability instead of productivity. This explains the importance of Question 1.

Based on Theorems 3 and 4 and the discussion in Subsection 6.1, it can be concluded that as long as the conditions of export markets and relevant exchange rates stay constant, then yes, the productivity advantage of firms involved in international trade naturally leads to profitability advantage over identical domestic firms. However, conditions of the export markets could change for the worse, exchange rates could fluctuate in unfavorable directions, and damaging events could break out unexpectedly at the height of international politics. Therefore, originally profitable operations could easily and quickly turn into losing propositions. This explains why empirical studies on Question 1 have been mixed without any definite conclusion [28].

On the other hand, by comparing Theorems 3 and 4, one can see clearly that exporting into less developed foreign markets could more likely turn productivity advantage into profitability advantage. It is because the sunk costs of exporting into such markets could be more easily covered, while the effect of the naturally built-in brand name could be employed to amplify the magnitude of profits. On the other hand, exporting into advanced markets does not naturally carry any built-in advantages other than facing intensified competition and rising costs. This end in fact is well confirmed by Wagner's empirical study [3] [48], where data from manufacturing enterprises of Germany show that any produc- 
tivity advantages of international trading firms are eaten up by extra costs related to selling and buying in foreign markets.

To address the second question, let us model a firm as an abstract yoyo, because each firm is an input-output system. Then we have one of the four scenarios shown in Figure 4. In Figure 4(a) the abstract firm is seen as the spinning yoyo with its inputs from the domestic market and its outputs provided to the same market. In Figure 4(b) the firm acquires its supplies from the domestic market while sells its outputs also to overseas markets beyond the domestic market. In Figure 4(c) the firm sells its products in the domestic market while imports at least some of its inputs from foreign markets. And, in Figure 4(d) the firm acquires inputs and sells outputs internationally.

For an input-output system to be stable there must be enough market forces to maintain the system so that both inputs and outputs of the system would be in equilibrium [9]. And for a spinning yoyo field to sustain itself there must be sufficient unevenness in the "material" distribution in the field of the yoyo body and the surrounding areas so that appropriate supplies are absorbed into the field and that abundant products are produced out of the field [7]. Hence, the domestic firm in Figure 4(a) and the multinational firm in Figure 4(d) would be most stable, while the firm in export markets in Figure 4(b) would be least stable depending on how long the domestic resources and supply of the firm could afford to sustain the international consumption, assuming all other conditions stay constant.

As for the difference between the domestic firm in Figure 4(a) and the firm with multinational exchange in Figure 4(d), because the latter is expected to experience more challenges than the former, that is, there is more unevenness in the "material" distribution in the yoyo field of the firm in Figure 4(d) than that of the domestic firm in Figure 4(a), if all other conditions stay constant, the latter firm is expected to enjoy a longer life span than the domestic firm. In the

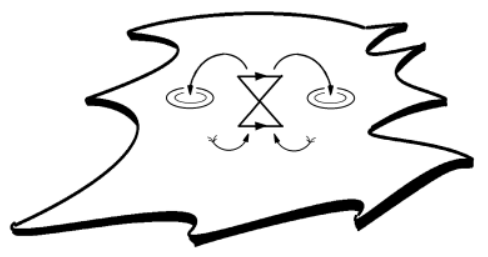

(a)

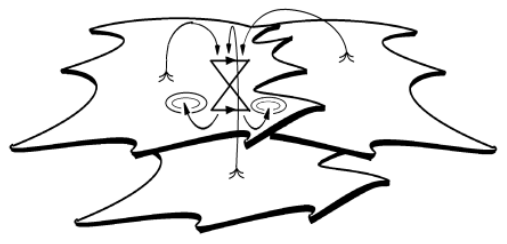

(c)

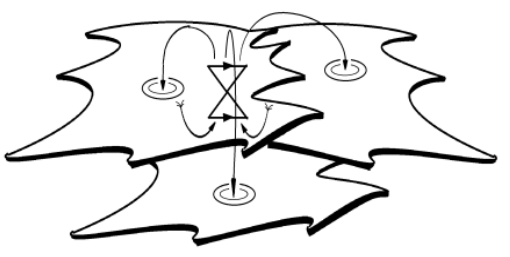

(b)

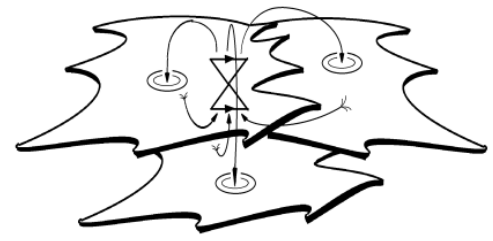

(d)

Figure 4. A systemic yoyo model of firms with/without international trade. (a) A domestic firm; (b) An exporting only firm; (c) An importing only firm; (d) An importing and exporting firm. 
terminology of business, firms involved in both imports and exports diversify their sales over different markets that have different business cycle conditions and/or in different phases of the product life cycle [49], and enjoys the benefit of combining the relative price and technology embodied in the imported products [50]. Consequently, firms involved in both imports and exports spread their risk while increasing their price and non-price competitiveness when compared to domestic firms. Additionally, based on the discussion in Subsection 6.1, as domestic firms are generally less efficient in terms of productivity and management than firms with international reach, one can expect that the former are more likely to fail than the latter [51].

As for the firm in Figure 4(b), which exports only, although it is the least stable among the four kinds of firms, the instability could potentially occur any moment when the national resources are drained over an exhaustively long time span. So, in the foreseeable future within which the supply of the needed resources is abundant, this firm is expected to do better than the domestic firm in Figure 4(a), because the export markets expand the magnitude of the domestic market (Theorems 3 and 4) and help to diversify the risk of the domestic market.

As for the firm in Figure 4(c), which imports only, although it is not as stable as those firms in Figures 4(a) and Figure 4(d), it is more stable than the firm in Figure 4(b). It is because the input-output yoyo field in Figure 4(c) always has abundant supplies (inputs), which could include capital, talents, better priced inputs, advanced technology, etc.

Based on what has been discussed above, the proposition below follows:

Proposition 1. Assume that all other conditions remain constant. Then the probability for firms involved in two-way trades to survive is expected to be the highest, followed by firms that only import, then firms that only export, and finally domestic firms.QED

This result is also empirically shown in parts in [49] [50] [52] [53] [54].

\section{Conclusions}

Recent theoretical or empirical studies on international trade and firm performance have enriched our knowledge on these related issues. Empirical works help uncover facts that hold true over space and time, while theoretical investigations provide capabilities for policy decision makers to reason beyond what available data are telling. Considering what has been established in the literature both theoretically and empirically, this work introduces systemic thinking and the systemic yoyo model into the literature. Consequently, we are able to confirm in theory the following big picture:

- Exporters and importers are more productive than non-exporters and non-importers, and that is true even in years prior to their start of exporting or importing;

- The number of export markets served increases with the firm's productivity, and exporters to more developed economies have superior ex-ante produc- 
tivity levels than non-exporters and firms exporting to less developed countries;

- Domestic firms are the least productive group, followed by firms that export and by firms that engage in outward foreign direct investment;

- Firms involved in exports and/or imports tend to be more profitable and pay higher wages and benefits than domestic firms; and

- The probability for firms involved in two-way trades to survive is expected to be the highest, followed by firms that only import, then firms that only export, and then domestic firms, assuming all other conditions stay constant.

Although the first three conditions stated above were supported by a large number of empirical studies using data from different countries, previous works suffered from the absence of a reasonably high degree of comparability due to differences in the unit of analysis (establishment vs. enterprise), the sampling frame (all firms versus only firms with a number of employees above a certain threshold only), the specification of the empirical models estimated, and the econometric methods applied, as pointed out by Wagner [28].

The present work is able to fill in voids in the literature where empirical studies are lacking due to unavailability of suitable data or in some cases inconsistent empirical conclusions were discovered [55]. For example, this paper confirms the presence of the effect of learning by exporting (and learning by importing), while pointing out the fact that exporting/importing does not necessarily improve the firms in general.

What is established in Section 6 helps to clear some of the empirical research topics regarding firms' survival. For example, one important topic for future research will be: Under what conditions would the given order of firms' survival in Proposition 1 be reversed?

The bottom line here is that by employing systemic thinking and the systemic yoyo model, we were able to develop a general theory on international trade and firm performance. Additionally, the theory also points to subareas where further empirical and theoretical studies are needed to uncover finer details.

Before we conclude this presentation, let us make a last remark. In the two sets of different symbolic modellings of the product markets, either domestic or foreign, developed in this paper, the demand side does not have to be made of households, although it seems to be throughout the previous sections, because the not-specified consumers (or buyers) could also be profit-maximizing firms as long as they make purchases. In other words, our models developed here also naturally cover the large and increasing share of exports and imports of intermediate goods that are part of international value chains.

As for limitations of this work, they are related to the implicit assumption employed throughout this paper: firms strive to succeed in the product marketplace. As a matter of fact, in the business world, not all firms are established in such ways. So, this fact opens up a large territory and space for future explorations. 


\section{Conflicts of Interest}

The authors declare no conflicts of interest regarding the publication of this paper.

\section{References}

[1] Bernard, A.B. and Jensen, J.B. (1995) Exporters, Jobs, and Wages in U.S. Manufacturing: 1976-1987. Brookings Papers on Economic Activity, Microeconomics, 26, 67-119.

[2] Melitz, M.J. (2003) The Impact of Trade on Intra-Industry Reallocations and Aggregate Industry Productivity. Econometrica, 71, 1695-1725. https://doi.org/10.1111/1468-0262.00467

[3] Wagner, J. (2016) A Survey of Empirical Studies Using Transaction Level Data on Exports and Imports. Review of World Economics, 152, 215-225. https://doi.org/10.1007/s10290-015-0235-8

[4] Melitz, M.J. and Redding, S.J. (2014) Heterogeneous Firms and Trade. Handbook of International Economics, 4, 1-54. https://doi.org/10.1016/B978-0-444-54314-1.00001-X

[5] McGrath, R.G. (2013) The End of Competitive Advantage: How to Keep Your Strategy Moving as Fast as Your Business. Harvard Business Review Press, Boston.

[6] von Bertalanffy, L. (1924) Einführung in Sprenglers Werk. Literaturblatt Kolnische Zeitung, May.

[7] Lin, Y. (2009) Systemic Yoyos: Some Impacts of the Second Dimension. Auerbach Publication, an Imprint of Taylor and Francis, New York.

[8] Klir, G. (1985) Architecture of Systems Problem Solving. Plenum Press, New York, NY.

[9] Lin, Y. (1999) General Systems Theory: A Mathematical Approach. Plenum and Kluwer Academic Publishers, New York.

[10] (1985) Mathematical Sciences: A Unifying and Dynamic Resource. Notices of the American Mathematical Society, 33, 463-479.

[11] Blauberg, I.V., Sadovsky, V.N. and Yudin, E.G. (1977) Systems Theory, Philosophy and Methodological Problems. Progress Publishers, Moscow.

[12] Klir, G. (2001) Facets of Systems Science. Springer, New York.

[13] Lin, Y. (2007) Systemic Yoyo Model and Applications in Newton's, Kepler's Laws, and Others. Kybernetes. The International Journal of Cybernetics, Systems and Management Science, 36, 484-516. https://doi.org/10.1108/03684920710747101

[14] Kline, M. (1972) Mathematical Thought from Ancient to Modern Times. Oxford University Press, Oxford.

[15] Wu, Y. and Lin, Y. (2002) Beyond Nonstructural Quantitative Analysis: Blown-Ups, Spinning Currents and Modern Science. World Scientific, River Edge, NJ.

[16] Lin, Y. (1988) Can the World Be Studied in the Viewpoint of Systems? Mathematical and Computer Modelling, 11, 738-742.

[17] Lin, Y., Ma, Y. and Port, R. (1990) Several Epistemological Problems Related to the Concept of Systems. Mathematical and Computer Modelling, 14, 52-57.

[18] Lin, Y. and Forrest, B. (2011) Systemic Structure behind Human Organizations: From Civilizations to Individuals. Springer, New York.

[19] Forrest, Y.L.J. (2013) A Systemic Perspective on Cognition and Mathematics. CRC Press, an Imprint of Taylor and Francis, Balkema, The Netherlands. 
[20] Forrest, Y.L.J. (2014) A Systems Perspective on Financial Systems. CRC Press, an Imprint of Taylor and Francis, Balkema, The Netherlands.

[21] Forrest, J.Y.L. and Tao, L.X. (2014) Investment and Employment Opportunities in China. CRC Press, an Imprint of Taylor and Francis, New York.

[22] Ying, Y.R. and Forrest, Y.L.J. (2015) Capital Account Liberation: Methods and Applications. CRC Press, an Imprint of Taylor and Francis, New York.

[23] Forrest, Y.L.J., Buttermore, J. and Wajda, T.A. (2017) At Nash Equilibrium When New Market Competitions Appear? Kybernetes. The International of Cybernetics, Systems and Management Science, 46, 256-271.

[24] Hide, R. (1953) Some Experiments on Thermal Convection in a Rotating Liquid. Quarterly Journal of the Royal Meteorological Society, 79, 161.

[25] Fultz, D., Long, R.R., Owens, G.V., Bohan, W., Kaylor, R. and Weil, J. (1959) Studies of Thermal Convection in a Rotating Cylinder with Some Implications for Large-Scale Atmospheric Motion. Meteorological Monographs, 4, 1-104.

[26] Bernheim, B.D. and Whinston, M.D. (1990) Multimarket Contact and Collusive Behavior. The RAND Journal of Economics, 21, 1-26.

[27] Lin, Y. and OuYang S.C. (2010) Irregularities and Prediction of Major Disasters. CRC Press, an Imprint of Taylor and Francis, New York, NY.

[28] Wagner, J. (2012) International Trade and Firm Performance: A Survey of Empirical Studies Since 2006. Review of World Economics, 148, 235-267. https://doi.org/10.1007/s10290-011-0116-8

[29] Forrest, J.Y.L. and Anderson, M. (2017) Customers' Indecisiveness: A Pricing Strategy Approach. Presented at the 2017 Annual Conference of Pennsylvania Economic Association, June 1-3.

[30] Sobel, R. (1999) When Giants Stumble: Classic Business Blunders and How to Avoid Them. Prentice Hall, Paramus, NJ.

[31] Bernard, A.B. and Jensen, J.B. (1999) Exceptional Exporter Performance: Cause, Effect, or Both? Journal of International Economics, 47, 1-25.

[32] Bernard, A.B. and Wagner, J. (1997) Exports and Success in German Manufacturing. Weltwirtschaftliches Archiv, 133, 134-157. https://doi.org/10.1007/BF02707680

[33] Wagner, J. (2007) Exports and Productivity: A Survey of the Evidence from FirmLevel Data. The World Economy, 30, 60-82. https://doi.org/10.1111/j.1467-9701.2007.00872.x

[34] Baldwin, R.E. and Robert-Nicoud, F. (2004) The Impact of Trade on Intraindustry Reallocation and Aggregate Industry Productivity: A Comment. NBER Working Paper Series, 10718.

[35] Wagner, J. (2007) Exports and Productivity in Germany. Applied Economics Quarterly, 53, 353-373.

[36] Wagner, J. (2008) Export Entry, Export Exit and Productivity in German Manufacturing Industries. International Journal of the Economics of Business, 15, 169-180. https://doi.org/10.1080/13571510802134270

[37] Singh, T. (2010) Does International Trade Cause Economic Growth? A Survey. The World Economy, 33, 1517-1564. https://doi.org/10.1111/j.1467-9701.2010.01243.x

[38] International Study Group on Exports and Productivity (ISGEP) (2008) Understanding Cross-Country Differences in Exporter Premia: Comparable Evidence for 14 Countries. Review of World Economics, 144, 596-635.

[39] Kasahara, H. and Lapham, B. (2013) Productivity and the Decision to Import and 
Export: Theory and Evidence. Journal of International Economics, 89, 297-316. https://doi.org/10.1016/j.jinteco.2012.08.005

[40] Andersson, M., Lööf, H. and Johansson, S. (2008) Productivity and International Trade: Firm Level Evidence from a Small Open Economy. Review of World Economics, 144, 774-801. https://doi.org/10.1007/s10290-008-0169-5

[41] Castellani, D., Serti, F. and Tomasi, C. (2010) Firms in International Trade: Importers' and Exporters' Heterogeneity in the Italian Manufacturing Industry. The World Economy, 33, 424-457. https://doi.org/10.1111/j.1467-9701.2010.01262.x

[42] Muuls, M. and Pisu, M. (2009) Imports and Exports at the Level of the Firm: Evidence from Belgium. The World Economy, 32, 692-734. https://doi.org/10.1111/j.1467-9701.2009.01172.x

[43] Altomonte, C. and Békés, G. (2010) Trade Complexity and Productivity. CeFiG Working Papers 12, September.

[44] Schank, T., Schnabel, C. and Wagner, J. (2007) Do Exporters Really Pay Higher Wages? First Evidence from German Linked Employer-Employee Data. Journal of International Economics, 72, 52-74. https://doi.org/10.1016/j.jinteco.2006.08.004

[45] Schank, T., Schnabel, C. and Wagner, J. (2010) Higher Wages in Exporting Firms: Self-Selection, Export Effect, or Both? First Evidence from Linked Employer-Employee Data. Review of World Economics, 146, 303-322. https://doi.org/10.1007/s10290-010-0049-7

[46] Serti, F., Tomasi, C. and Zanfei, A. (2010) Who Trades with Whom? Exploring the Links between Firms' International Activities, Skills, and Wages. Review of International Economics, 18, 951-971. https://doi.org/10.1111/j.1467-9396.2010.00919.x

[47] Foster, L., Haltiwanger, J. and Syverson, C. (2008) Reallocation, Firm Turnover, and Efficiency: Selection on Productivity or Profitability? American Economic Review, 98, 394-425.

[48] Wagner, J. (2012) Exports, Imports and Profitability: First Evidence for Manufacturing Enterprises. Open Economies Review, 23, 747-765. https://doi.org/10.1007/s11079-011-9235-Z

[49] Wagner, J. (2013) Exports, Imports and Firm Survival: First Evidence for Manufacturing Enterprises in Germany. Review of World Economics, 149, 113-130. https://doi.org/10.1007/s10290-012-0141-2

[50] Gibson, M.J. and Graciano, T.A. (2011) Costs of Starting to Trade and Costs of Continuing to Trade. Washington State University, Mimeo, January.

[51] Baldwin, J. and Yan, B.L. (2011) The Death of Canadian Manufacturing Plants: Heterogeneous Responses to Changes in Tariffs and Real Exchange Rates. Review of World Economics, 147, 131-167. https://doi.org/10.1007/s10290-010-0079-1

[52] Vogel, A. and Wagner, J. (2010) Higher Productivity in Importing German Manufacturing Firms: Self-Selection, Learning from Importing, or Both. Review of World Economics, 145, 641-665. https://doi.org/10.1007/s10290-009-0031-4

[53] López, R.A. (2006) Imports of Intermediate Inputs and Plant Survival. Economics Letters, 92, 58-62. https://doi.org/10.1016/j.econlet.2006.01.025

[54] Namini, J.E., Facchini, G. and López, R. (2011) Export Growth and Factor Market Competition: Theory and Evidence. Department of Economics, Erasmus University Rotterdam, Mimeo.

[55] Silva, A., Africano, A.P. and Afonso, Ó. (2012) Learning-by-Exporting: What We Know and What We Would Like to Know. The International Trade Journal, 26, 255-288. https://doi.org/10.1080/08853908.2012.682022 